enfoque

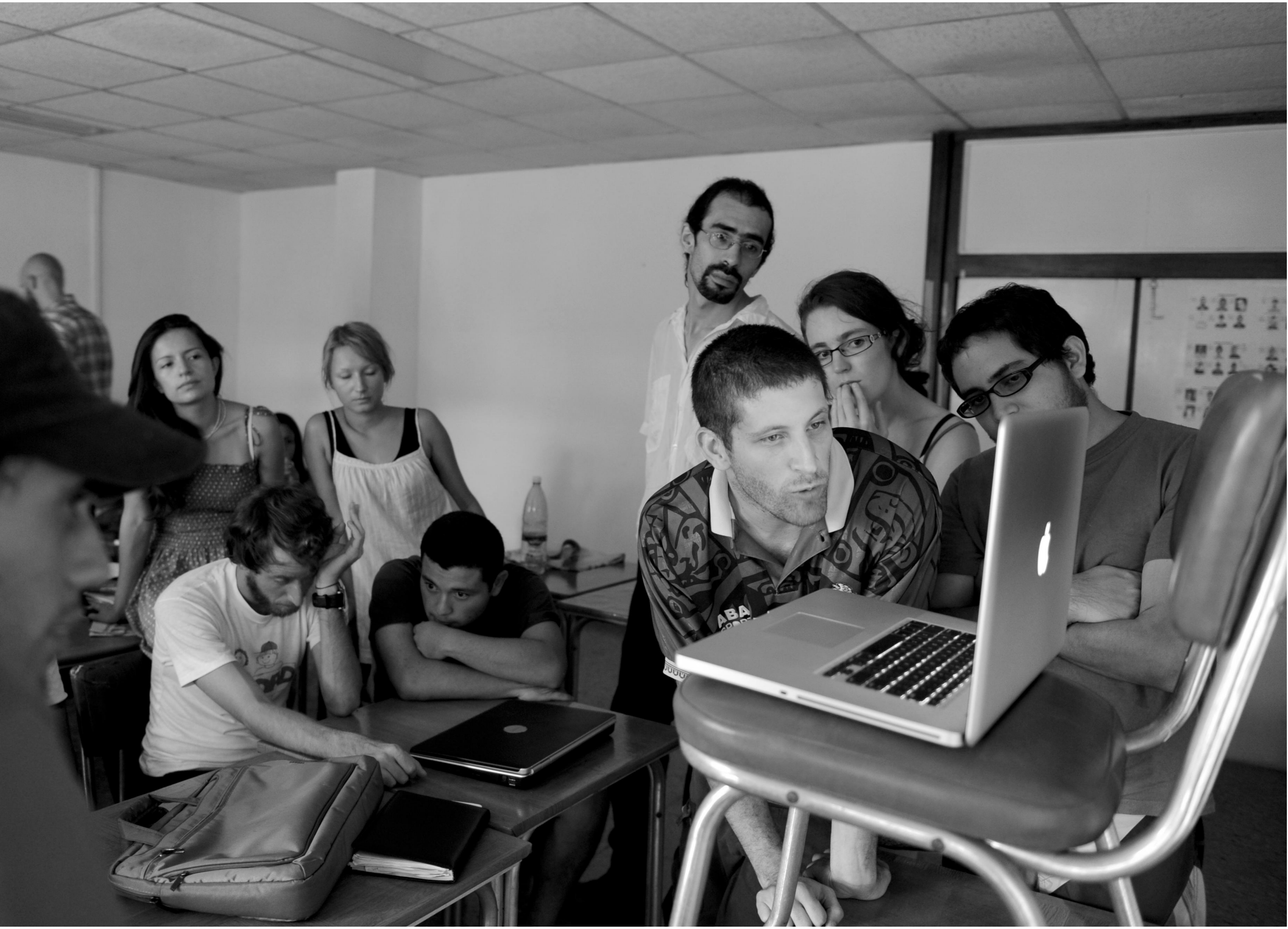

\title{
Nativos e inmigrantes digitales: ¿cómo aprendemos y enseñamos?
}

Por Julia Leymonié

Fotos de Pablo Porciúncula 
"En el pasado, la educación adquiría muchas formas y demostró ser capaz de ajustarse a las cambiantes circunstancias, fijándose nuevos objetivos y diseñando nuevas estrategias. Pero, lo repito, el cambio actual no es como los cambios del pasado. En ningún otro punto de inflexión de la historia humana los educadores debieron afrontar un desafío estrictamente comparable con el que nos presenta la divisoria de aguas contemporánea. Sencillamente nunca antes estuvimos en una situación semejante. Aún debemos aprender el arte de vivir en un mundo sobresaturado de información. Y también debemos aprender el aún más difícil arte de preparar a las nuevas generaciones para vivir en semejante mundo".

La educación juega un papel fundamental en el desarrollo de una sociedad. Es por eso que los sistemas educativos deben estar atentos a las características del momento histórico, a las demandas sociales, a los intereses de los ciudadanos y a las metas que la sociedad se propone alcanzar. En este artículo trataremos de motivar la reflexión del lector acerca del impacto de las tecnologías de la información y la comunicación (TIC) sobre las formas de enseñar y de aprender en la universidad. La mirada no es objetiva, sino que proviene de alguien que adhiere a la idea de que los jóvenes desarrollan útiles e interesantes competencias comunicativas en contextos informáticos y digitales que, lamentablemente, no tienen oportunidad de usar dentro de las aulas.

La mayoría de los adultos de hoy hemos vivido la mayor parte de nuestra vida en la modernidad "sólida", y en ese marco nos hemos educado. Fuimos a la escuela y a la universidad en una época en que se pensaba que el mundo era estable y duradero. Al decir de Bauman, ${ }^{2}$ la modernidad "sólida" está llegando a su fin para dar paso al estado "líquido" de la sociedad. La metáfora propuesta por el filósofo polaco nos parece muy pertinente e ilustrativa para comprender el fenómeno del cual somos observadores y participantes. Bauman utiliza conceptos de la física para explicar su visión de la sociedad actual: las moléculas de los cuerpos sólidos están ordenadamente distribuidas dentro de un retículo rígido y que, por el contrario, las moléculas de los líquidos están más desordenadas y en continuo movimiento. Es por esto que los sólidos tienen una cierta forma que perdura en el tiempo, mientras que los líquidos fluyen y adquieren las formas de los recipientes que los contienen. La metáfora nos habla de una sociedad que está experimentando un pasaje desde un estado "sólido", estable, previsible, a otro estado "líquido", flexible, incierto, cambiante, donde las instituciones tradicionales van perdiendo paulatinamente su capacidad para sostenerse en el tiempo y para constituirse en referencia para los individuos.

Las oportunidades que ofrece el mundo hoy son tantas que ninguna persona tendría la posibilidad de explorarlas. "En un mundo así" -señala Bauman- "no hay casi nada predeterminado, y menos aún irrevocable. Pocas derrotas son definitivas, pocos contratiempos son irreversibles y pocas victorias son esenciales".

Los docentes, formados en un escenario de solidez, nos enfrentamos al desafío de educar personas que se van a desempeñar en una sociedad caracterizada por la incertidumbre, la innovación y la fluidez. Uno de los rasgos más salientes del nuevo escenario es la rápida circulación de la información, justificándose el amplio uso de expresiones como "segunda revolución industrial", "sociedad de la información", "sociedad del conocimiento" o "revolución digital". Se trata de expresiones que se refieren a un tipo de sociedad basada en la información y el conocimiento, gestionados por las nuevas tecnologías.

Tanto el tiempo como el espacio se encuentran alterados. Castells" se refiere al "tiempo atemporal”, rescatando la idea kantiana de que nuestra
Julia Leymonié Sáenz:: (Montevideo) es magister en Educación (Universidad Católica del Uruguay en convenio con la Universidad de Lovaina) y licenciada en Ciencias Biológicas (Facultad de Humanidades y Ciencias, Universidad de la República). Es profesora de Física de Enseñanza Media y docente en la Universidad Católica del Uruguay y el Instituto Universitario Claeh; fue docente en la Universidad de la República. Ha sido investigadora en las universidades de Lovaina, Harvard y Michigan. Desde el 2007 es directora del "Programa de Mejora de la Docencia Universitaria" en la Universidad Católica del Uruguay.

\footnotetext{
Bauman, Z. Los retos de la educación en la modernidad liquida. Barcelona: Gedisa. 2008. p. 46. 2 :. Bauman, Z. Modernidad liquida. Buenos Aires: Fondo de Cultura Económica. 1999. 3:: Bauman, Z. Op.cit, 1999. Pp. 66. 4:: Castells, M. La era de la Información. Siglo XXI: México.
} 2001. 
comprensión del entorno depende del instrumento con el cual lo estamos registrando. Estas son épocas del "mundo digital" (Negroponte, 1996). ${ }^{5}$ Igualmente, los espacios geográficos comienzan a ser sustituidos por los mapas de la realidad virtual.

Nuevas generaciones, nuevos entornos tecnológicos

Identifiquemos algunas características de esta sociedad actual. Una primera observación se relaciona con el valor que hoy los ciudadanos otorgamos al conocimiento. Si bien ha sido importante desde siempre, hoy jerarquizamos el conocimiento como un valor social clave para asegurar la calidad de la vida para todos. Comenzamos a valorar más el capital cultural y el talento que las capacidades laborales específicas: la disposición a la formación permanente, la creatividad y el talento son cualidades deseadas a la hora de seleccionar recursos humanos. Se trata de un momento en el que los conocimientos se aplican a la producción en forma casi instantánea, de tal manera que las ventajas competitivas radican en la propia generación de los mismos.

En segundo lugar, podemos observar cada vez más una "ciudadanía planetaria" o global, donde las identidades individuales se van desvaneciendo, para disgregarse y entramarse al interior de las comunidades virtuales. Se trata de identidades que se definen en base a criterios globales, sincrónicos y sistémicos.

Una tercera característica importante es que las herramientas tecnológicas permiten la información al instante. El desarrollo tecnológico busca la flexibilidad, así como incorporarse al mayor número posible de dimensiones de la vida humana. La relevancia que ha alcanzado en el mundo de hoy la información -símbolo de poder en todas las sociedades- no tiene símil en lo que va de la historia humana. El impacto de las nuevas tecnologías y el reconocimiento explícito de que el poder y la información están indisolublemente unidos podrían resumir las razones por las cuales hoy atribuimos a la información un valor social inestimable.

Muy relacionado con el punto anterior, en términos de las formas de relacionamiento entre las personas y las organizaciones, es posible observar que las redes sociales han comenzado a tomar el lugar que antes ocupaban únicamente las estructuras sociales tradicionales, como las corporaciones, las universidades y hasta los gobiernos. La organización en redes virtuales y sinérgicas son flexibles, horizontales y existe una comunicación fluida entre los puestos directivos y de base.

Los estudios sobre las nuevas prácticas sociales producto de los cambios en las formas y medios de interacción y socialización de las personas permiten identificar algunas características interesantes de esta sociedad "líquida", desbordante de generación y circulación de información:

- Las relaciones y manifestaciones sociales tienen un alto nivel de incertidumbre.

- Las personas, cada vez más, deben hacerse responsable de las tareas sociales (carencia de soportes socioculturales permanentes $\mathrm{y}$ estables).

- La formación de nodos y redes personales e institucionales que van más allá de las estructuras organizativas tradicionales.

- Los cambios en las formas de comunicación.

- Las nuevas formas de producción de informaciones desarrolladas por los usuarios de las TIC.

En el año 2001, Marc Prensky ${ }^{6}$ afirmó que nos estábamos enfrentando a la primera generación que había crecido en un verdadero y completo entorno tecnológico. Al decir de este autor, en los primeros años del siglo iba preparándose una "singularidad tecnológica", ${ }^{7}$ o sea un evento au- 
gural de una aceleración pronunciada del progreso tecnológico y del cambio social, alterando de tal manera el ambiente que cualquier humano anterior a tal evento sería incapaz de comprender y/o asumir. Es un concepto que ya fue utilizado en la década del cincuenta y que fue popularizado por Vinge ${ }^{8}$ en los ochenta. Aún se debate si la singularidad ocurrirá o no, o si ya ha ocurrido.

En una entrevista publicada recientemente en Internet, Ray Kurzweil ${ }^{9}$ sostiene que dentro de un cuarto de siglo, la inteligencia no biológica va a igualar el alcance y la sutileza de la inteligencia humana, y que incluso la va a sobrepasar, debido a la aceleración continua de las tecnologías de la información, así como la capacidad de las máquinas para compartir instantáneamente su conocimiento. Cada vez más, los fondos destinados a investigaciones, en los países de punta, se vuelcan a los laboratorios de ingeniería emocional y de robótica humanizada, lo cual muestra que las tradicionales barreras levantadas por académicos e instituciones van siendo derribadas sin remedio.

En este marco interactúan socialmente, por lo menos, dos perfiles de personas: los nativos digitales y los inmigrantes digitales. ${ }^{10}$ Los "nativos digitales" 11 son personas que han nacido y crecido en escenarios donde proliferan las tecnologías asociadas a la informática masiva (como Internet, blogs, Twitter, Youtube, Facebook, entre otras) y a la telefonía celular multipropósito. Prensky denomina "inmigrantes digitales" a las personas que en algún momento de sus vidas han adoptado las nuevas tecnologías como herramienta o como diversión, pero lo hacen con "acento". Por ejemplo, imprimen un documento digital para leerlo, o llaman por teléfono para asegurarse que el mail enviado llegó a destino.

Siguiendo con esta metáfora, los inmigrantes se encuentran hoy en proceso de incorporar una "segunda lengua”, a diferencia de los nativos, para quienes el lenguaje digital es su "primera lengua".
Sabemos, además, que las zonas del cerebro que se activan en uno y otro caso son diferentes, lo que marca una diferencia sustancial entre unos y otros, pero aún hay pocos estudios sobre lo que esto significa en términos sociales.

La conceptualización de Prensky entre nativos e inmigrantes, demasiado simplificadora de la situación real, ha sido complementada por otros autores. Piscitelli, ${ }^{12}$ por ejemplo, señala que entre los que nacieron antes de los años ochenta, es necesario distinguir entre quienes han incorporado y manejan con flexibilidad las herramientas tecnológicas, a quienes denomina "mediadores intergeneracionales”, y los inmigrantes digitales ya definidos por Prensky. Además, agrega la categoría de los "excluidos digitales", que son aquellos que no acceden a las tecnologías ya sea porque no saben o porque no quieren. Piscitelli nos recuerda, además, que casi la mitad de la población mundial ni siquiera puede ser clasificada, porque son personas que viven en la miseria.

Los retos de los docentes en este contexto Resulta imposible desconocer la existencia de una brecha cognitivo - emocional entre las diferentes generaciones. Se trata de una importante grieta, difícil de cerrar, y que presenta fuertes implicancias cognitivas, psicológicas y pedagógicas. Los estudiantes de hoy son "nativos digitales", sobre todo quienes tienen entre 4 y 16 años, que han nacido en una sociedad de computadoras, teléfonos celulares y video juegos, y que están inmersos en el océano de Internet.

"Nuestros estudiantes han cambiado radicalmente. Los estudiantes de hoy ya no son los que nuestro sistema educativo estaba preparado para enseñar". ${ }^{13}$

Estos estudiantes están acostumbrados a manejar la información aceleradamente y en paralelo. Son chicos "multitarea": las imágenes los estimulan más que los textos escritos y prefieren trabajar

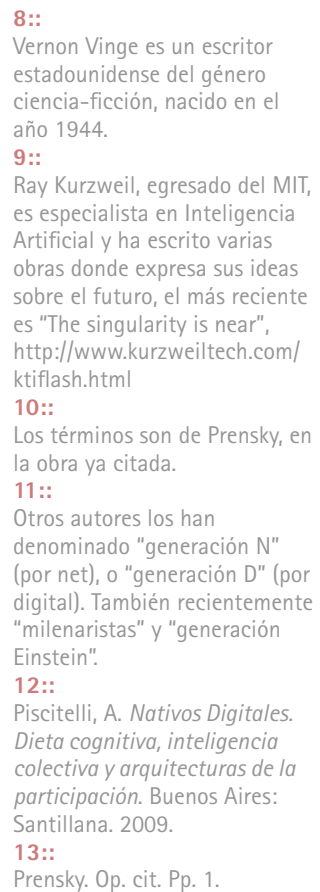




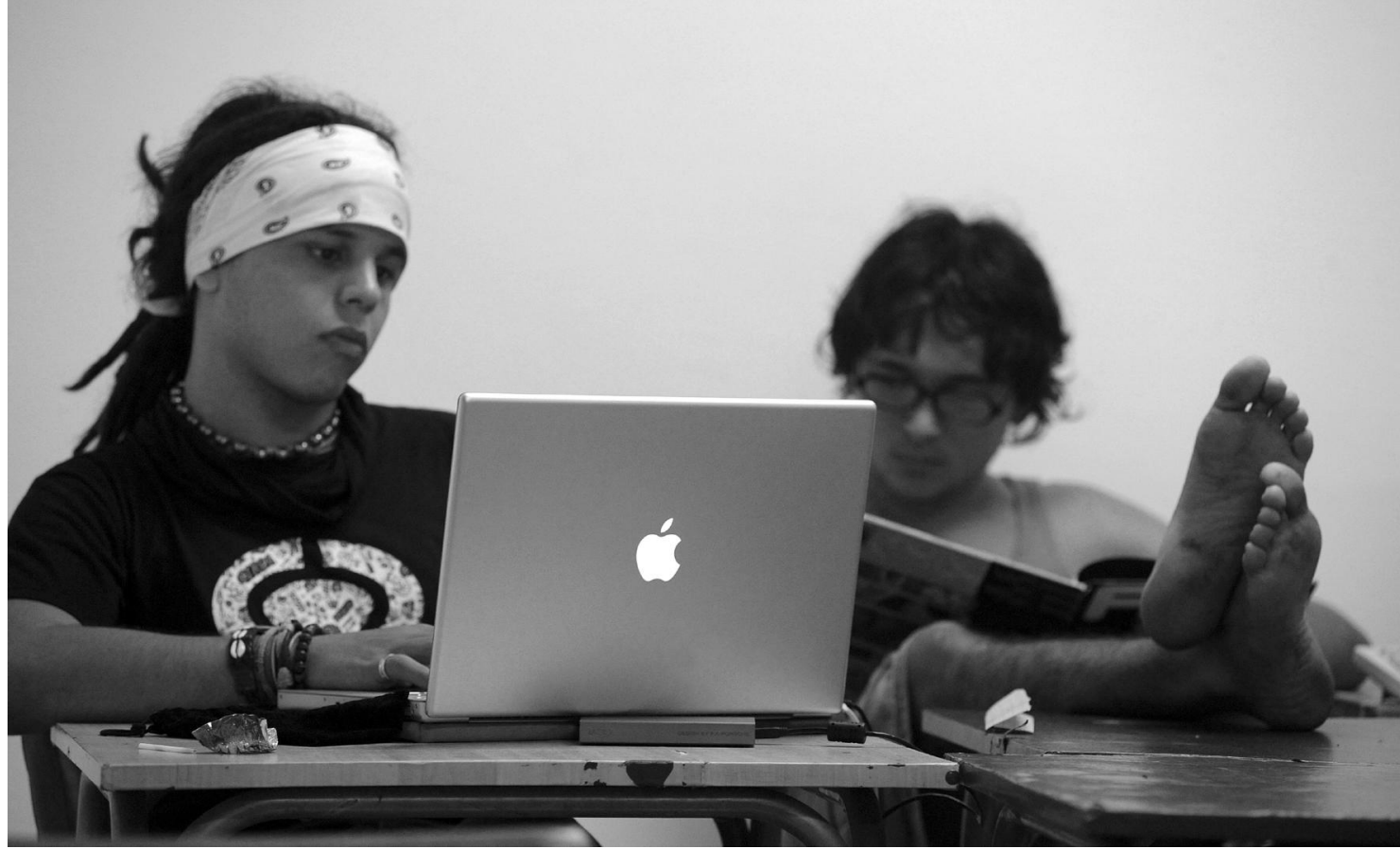

en redes. Son poco pacientes para las tareas con muchos pasos y para las clases de tipo transmisivo. Optan por las soluciones rápidas y directas. Necesitan estímulos positivos y retroalimentación frecuente. La inteligencia emocional parece ser un factor, en cierta medida, responsable de las habilidades cognitivas de las personas, ${ }^{14}$ por lo cual los nativos digitales probablemente estén en condiciones especialmente interesantes para aprender lo que les produce emoción. Las instituciones educativas, en su mayoría, no están preparadas para incorporar este concepto dentro de sus marcos teóricos. ${ }^{15}$

Los docentes somos, mayoritariamente, inmigrantes; en el mejor de los casos somos inmigrantes competentes, o mediadores intergeneracionales. El desafío no es menor. Es necesario que los docentes incorporemos nuevos conocimientos acerca de los modos de aprender de los nativos y, en función de ese conocimiento, seamos capaces de reacondicionar los ambientes de aprendizaje. A. El error de Descartes. La razón de las emociones. Andrés Bello: Santiago. 1996.

OCDE. La comprensión de cerebro. Hacia una nuevo ciencia del aprendizaje. Auta XXI. Santillana: México. 2003.
Es necesario reconocer los cambios que las nuevas formas de comunicación han producido y están produciendo, en la inteligencia personal de los individuos, así como en la inteligencia colectiva. Ambas son interdependientes. La inteligencia colectiva se ha visto favorecida por las po- sibilidades de almacenar información en soporte digital y procesarla con gran celeridad, así como por la capacidad de resolver problemas complejos usando la robótica y las funciones automáticas.

En este escenario complejo y diverso, el sistema educativo debe encarar las transformaciones necesarias para abordar las nuevas problemáticas didácticas y pedagógicas. Es mucho más que realizar un cambio metodológico, se trata de una inflexión epistemológica dentro de las concepciones docentes sobre el enseñar y el aprender.

Los adultos, en particular los docentes, solemos pensar que las formas de aprender de los estudiantes actuales son similares a las que empleábamos nosotros mismos, y que las estrategias de enseñanza y la organización escolar funcionarán hoy de igual modo que hace 30 o 40 años. Es necesario asumir que esto no es así, y que la única solución para retener a los estudiantes dentro de los sistemas educativos formales es desformalizar los sistemas.

Actualmente, la alfabetización para los nuevos lenguajes audiovisuales e informáticos no se aprende en la escuela. Los niños y jóvenes realizan aprendizajes autónomos e intuitivos, a partir 
de sus capacidades innatas de exploración y de ensayo. Así, las instituciones educativas tradicionales están tambaleantes en la sociedad de la información. Dice Martín Barbero: "La sociedad cuenta hoy con dispositivos de almacenamiento, clasificación, difusión y circulación mucho más versátiles, disponibles e individualizados que la escuela". ${ }^{16}$ Las instituciones educativas, entre ellas la universidad, no son los únicos lugares donde es posible encontrar "el saber". La función básica de conservación y trasmisión de los saberes, de una determinada cultura, ha sido alterada.

La pérdida del valor social de la institución escolar se ve reflejada en la disminución de la legitimidad de los conocimientos y las habilidades de los maestros y profesores. Los estudiantes, sean pequeños, adolescentes o jóvenes, disponen de innumerables herramientas que permiten poner en discusión los saberes escolares impartidos por sus docentes. Hoy el conocimiento se encuentra disperso, y es necesario ir en su búsqueda con cierto grado de autonomía. Las escuelas no están preparando a los estudiantes para esa búsqueda. “(...) la escuela no facilita el ambiente de libertad -en algunos casos en lo físico y lo temporalque requiere el saber disperso en nuestros dias, y, cada vez más, los estudiantes se ven forzados a explorar este saber autónomamente". ${ }^{17}$

Es así que el sistema educativo actual, en su conjunto, está perdiendo aceleradamente las funciones tradicionales que la sociedad le tenía adjudicadas, y se encuentra luchando para recuperar algunas o encontrar nuevas funciones, enfrentándose a desafíos de gran envergadura. A fines del siglo pasado ya se visualizaban estos retos. El Informe de la Comisión Internacional sobre Educación para el Siglo XXI, realizado para la UNESCO y conocido como Informe Delors, ${ }^{18}$ planteaba visionariamente, en el año 1996, el concepto de "sociedad educativa", donde todo puede ser motivo para aprender y desarrollar al máximo las capacidades de cada individuo. Éste es el marco en que se ubica hoy la universidad.
Hay autores -como el citado Bautista- ${ }^{19}$ que plantean que la institución universitaria vive en estos últimos años el cambio más significativo desde su origen. La universidad se ha visto obligada a repensarse a sí misma, a fin de acompañar los vertiginosos cambios que se están produciendo en las estructuras sociales, científicas, económicas y educativas.

En cierto sentido, dentro del sistema educativo, la institución universitaria y, particularmente, su cuerpo docente, han sido los más resistentes a las transformaciones didáctico-pedagógicas. Si bien comienzan a circular nuevas formas de enseñar y nuevas formas de evaluar, el ámbito universitario todavía está muy lejos de las necesarias reformas que exige la sociedad de hoy.

Los cambios en la educación universitaria

Es posible analizar la situación de la educación universitaria bajo dos dimensiones: la formación y el contexto. Desde el punto de vista de la formación, hoy se espera que un egresado universitario haya desarrollado, dentro de las aulas de la universidad, ciertas competencias básicas, además de las específicas propias de su profesión. Estas competencias básicas están referidas a la capacidad de trabajar en equipo, al desarrollo de pensamiento autónomo y a la disposición al aprendizaje permanente.

Las nuevas propuestas pedagógicas apelan, por lo tanto, a que los estudiantes se comprometan con su aprendizaje y se constituyan en los verdaderos protagonistas del hecho educativo. Los nuevos enfoques privilegian la comprensión de los contenidos y la adquisición de competencias por parte del estudiante, antes que la trasmisión de conocimientos por parte del profesor. Así, se espera que el estudiante juegue un papel activo en la construcción de su bagaje intelectual, mientras el docente abandona su rol trasmisor para pasar a cumplir el papel de orientador y organizador de contenidos y tareas. comunicativo". En Comunicar, № 13. 1999. Pp. 14 17:: Pérez Tornero, J.M Comunicación y educación en la sociedad de la información. la sociedad de la informac Paidós: Barcelona. 2000. 18:

Delors, J. La educación encierro un tesoro. Madrid: Santillana. 1996. 19:

Bautista, G., Borges, F. \&t Forés A. Didáctica Universitaria en entornos virtuales de enseñanza y aprendizaje. Madrid: Narcea.2009. 


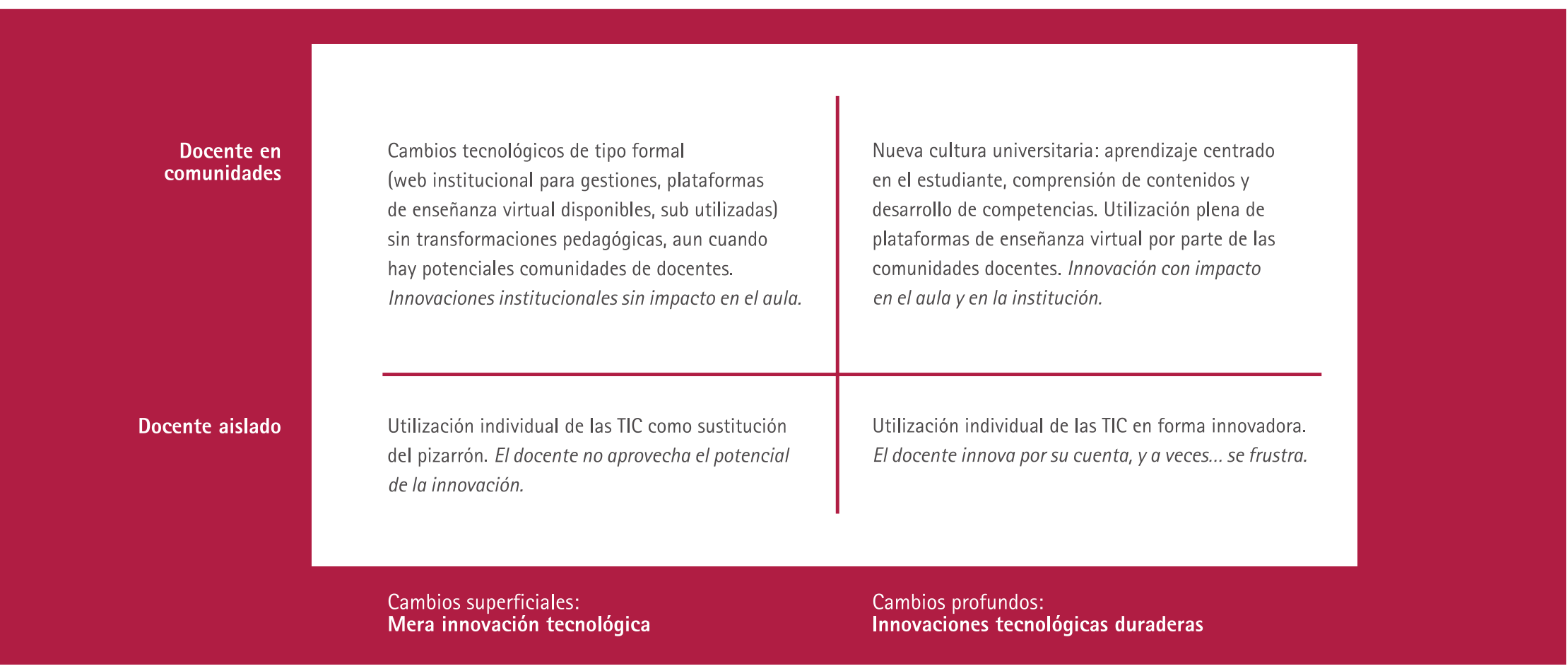

Esquema: Cuatro situaciones de las universidades actuales.

La tarea del docente, por su parte, debe experimentar cambios. Ya no es posible imaginar un docente aislado en su aula, planificando en soledad. Se espera que se conformen comunidades de docentes, que colaborativamente desarrollen las complejas tareas docentes que demanda la universidad de hoy. ${ }^{20}$

En lo que se refiere al contexto de aprendizaje, ya no se concibe una única forma de enseñar y de aprender. La situación de acción didáctica debe incluir elementos innovadores, que abran posibilidades a diversos escenarios de trabajo, que atiendan a los diferentes estilos cognitivos, y a las múltiples inteligencias que despliegan los sujetos involucrados en el enseñar y el aprender. ${ }^{21}$ Las tecnologías de la comunicación y de la información brindan herramientas muy adecuadas para la construcción de los nuevos ambientes de aprendizaje, así como para la construcción de las comunidades docentes. Los docentes hemos sido formados en contextos de presencialidad, y así enseñamos, llegando a obtener un buen dominio de este escenario. Hoy, nos vemos desafiados a complementar nuestras clases presenciales con acciones docentes de tipo virtual, y aun a encarar cursos totalmente virtuales. La preparación de este nuevo enfoque de las situaciones didácticas, su diseño y planificación, los contenidos a enseñar $-\mathrm{y}$, por lo tanto, la información a suministrar-, los recursos a usar, las formas de evaluar... todo necesita ser repensado.

Desde fines del siglo XX, formación y contexto se han constituido en una importante preocupación para las universidades, las cuales han ido incorporando, lentamente, en la medida de sus posibilidades, transformaciones de distinto nivel. El esquema muestra gráficamente cuatro situaciones típicas que pueden ser encontradas actualmente en universidades de nuestro medio. 
La nueva cultura universitaria, someramente caracterizada en el cuadrante superior derecho, remite a la situación ideal, hacia la cual deberían tender las instituciones universitarias capacitando a sus docentes para lograr innovaciones profundas y duraderas, en el marco de comunidades docentes. Éstas son verdaderos equipos de aprendizaje cooperativo, ${ }^{22}$ que se sostienen en base al apoyo, estímulo y ayuda de los pares entre sí. El desarrollo, transferencia y mantenimiento de una innovación dependen, en buena medida, de que los docentes se organicen en equipos cooperativos "que se ocupen de ayudar a que cada miembro mejore de manera progresiva su competencia en el uso del aprendizaje cooperativo". Pero no basta con el esfuerzo del cuerpo docente, es necesario que la gestión de la institución esté preparada y apoye activamente la innovación. De lo contrario, probablemente se de la situación descrita en el cuadrante superior izquierdo.

Hoy en día, en la universidad, nos encontramos fundamentalmente con las situaciones caracterizadas en los cuadrantes inferiores. Dice Rodríguez Izquierdo: "Las instituciones de educación superior son bien conocidas por su capacidad para proteger las actividades tradicionales básicas de la injerencia externa, lo que puede explicar la falta de efectos directos de las TIC. La tiza y la palabra siguen siendo el uso dominante y legitimo en muchas instituciones". ${ }^{23}$ El trabajo del docente aislado, preparando sus clases en forma individual, sin formar parte de una comunidad que toma decisiones acerca de qué enseñar y cómo hacerlo, es una constante. Algunos introducen recursos tecnológicos que facilitan la comunicación con los estudiantes y que favorecen su autonomía; estas modificaciones en sus prácticas pueden ser consideradas verdaderas innovaciones. Suele suceder que estos docentes sufren frustraciones frecuentes, al no tener el apoyo de los pares y de la propia institución, que no está preparada para albergar innovaciones. A veces el discurso de la institución así lo plantea, pero luego el ejercicio concreto de la gestión lo impide. Muchos otros docentes se limitan a usar los recursos tecnológi- cos que la institución le ofrece, en su forma más primitiva; otros no se apoyan en ningún recurso tecnológico.

Nuevas maneras de aprender: el reto de los estudiantes

También los estudiantes deben prepararse para los cambios culturales que implica entender el aprendizaje como un compromiso personal. Ya vimos que la mayoría de los estudiantes universitarios actuales se pueden definir como "nativos digitales”. No alcanza con manejar las tecnologías de la información y la comunicación con flexibilidad en contextos informales, básicamente de entretenimiento y distracción, sino que es un desafío que los "nativos digitales" sean capaces de aplicar sus habilidades en contextos de educación y de trabajo.

Los jóvenes transitan por un sistema educativo que aún se encuentra de espaldas a las transformaciones pedagógicas que exige el contexto actual y, por ello, se han adaptado a la pasividad del receptor o, en el peor de los casos, han desertado debido al fracaso. La mayoría de los modelos didácticos que han tenido oportunidad de vivir son tradicionales, basados en la trasmisión del conocimiento. Aun aquellos pocos docentes que han presentado otras formas de trabajo didáctico no impactan lo suficiente en la experiencia escolar de los estudiantes. El modelo transmisivo es un modelo dominante.

Los estudiantes deben aprender el rol de ser activos y autónomos, en contraposición con el rol de estudiante tradicional. Este pasaje es gradual, y se produce siempre que exista un contexto de aprendizaje que estimule la actividad y la autonomía. Este contexto debe ser construido por docentes e institución en forma conjunta: es una acción colectiva.

El estudiante tradicional dispone de un estrecho margen de decisión respecto a la organización de su propio aprendizaje, dependiendo fundamen-

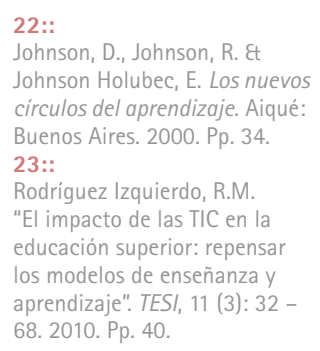




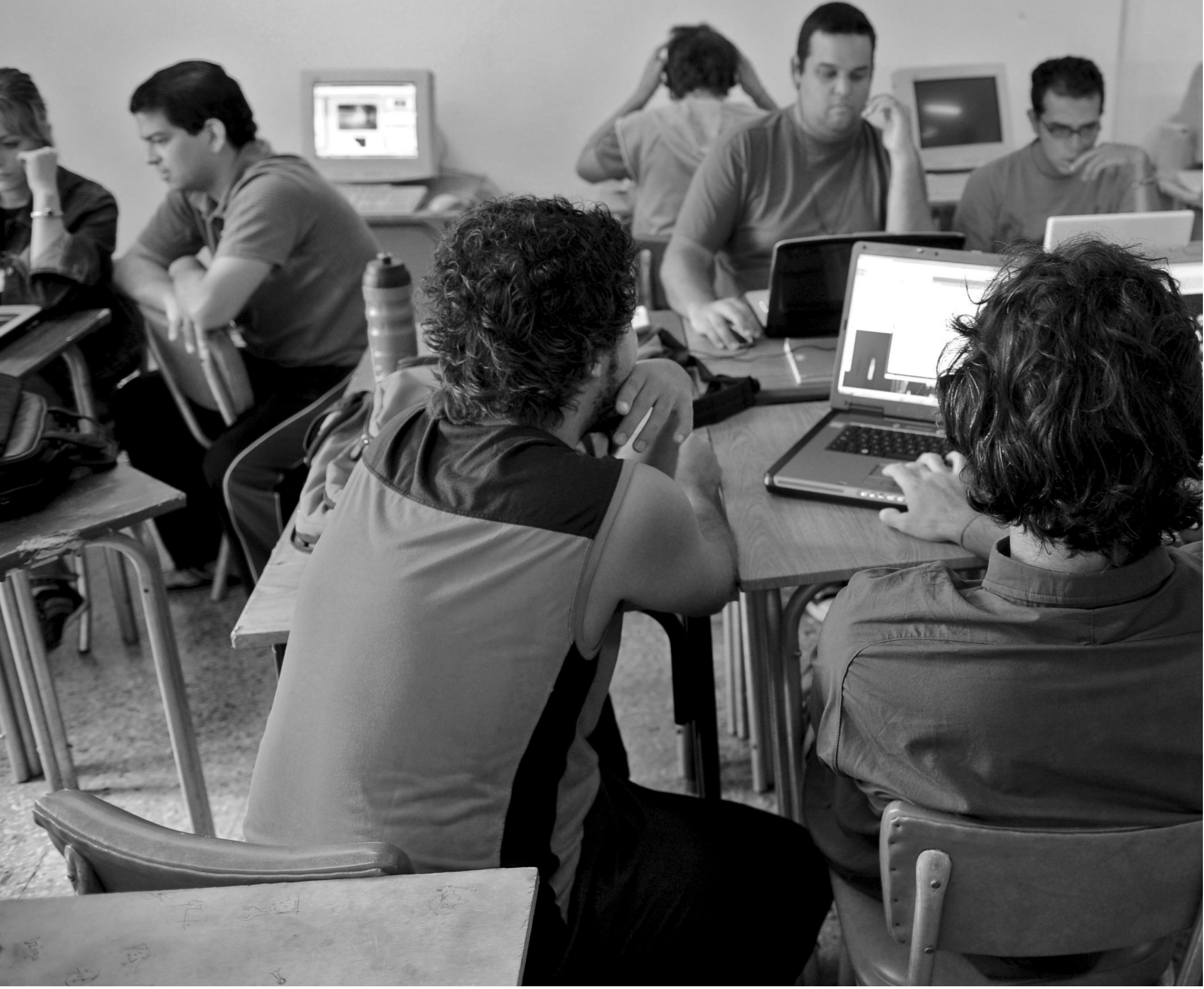

talmente de las decisiones del docente. Tiene una implicación escasa o nula en la construcción de sus conocimientos, y las habilidades que desarrolla, clave de su éxito en los estudios, son de tipo principalmente memorístico. Esta clase de estudiante suele enfrentarse duramente a los problemas de la práctica cuando egresa y sale al campo laboral. No ha tenido oportunidad de aplicar sus conocimientos, en forma autónoma, a los auténticos problemas que se presentan en la profesión que eligió.

Esperamos que el estudiante del siglo XXI tenga una actitud proactiva, debido a que la educación le proporciona oportunidades para tomar decisio- 
